BMJ Paediatrics Open

\section{What is the timeliness and extent of health service use of Victorian (Australia) children in the year after entry to out-of-home care? Protocol for a retrospective cohort study using linked administrative data}

To cite: McLean $\mathrm{K}$, Hiscock $\mathrm{H}$, Scott $\mathrm{D}$, et al. What is the timeliness and extent of health service use of Victorian (Australia) children in the year after entry to out-ofhome care? Protocol for a retrospective cohort study using linked administrative data. BMJ Paediatrics Open 2019;3:e000400. doi:10.1136/ bmjpo-2018-000400

Received 28 0ctober 2018 Revised 28 November 2018 Accepted 29 November 2018

Check for updates

(c) Author(s) (or their employer(s)) 2019. Re-use permitted under CC BY-NC. No commercial re-use. See rights and permissions. Published by BMJ

For numbered affiliations see end of article.

Correspondence to Dr Karen McLean; karen. mclean@rch.org.au

\section{ABSTRACT}

Introduction Children entering out-of-home care have high rates of health needs across all domains of health. To identify these needs early and optimise long-term outcomes, routine health assessment on entry to care is recommended by child health experts and included in policy in many jurisdictions. If effective, this ought to lead to high rates of health service use as needs are addressed. Victoria (Australia) has no state-wide approach to deliver routine health assessments and no data to describe the timing and use of health service visits for children in out-of-home care. This retrospective cohort data linkage study aims to describe the extent and timeliness of health service use by Victorian children (aged 0-12 years) who entered out-of-home care for the first time between 1 April 2010 and 31 December 2015, in the first 12 months of care.

Methods and analysis The sample will be identified in the Victorian Child Protection database. Child and placement variables will be extracted. Linked health databases will provide additional data: six state databases that collate data about hospital admissions, emergency department presentations and attendances at dental, mental and community health services and public hospital outpatients. The federal Medicare Benefits Schedule claims dataset will provide information on visits to general practitioners, specialist physicians (including paediatricians), optometrists, audiologists and dentists. The number, type and timing of visits to different health services will be determined and benchmarked to national standards. Multivariable logistic regression will examine the effects of child and system variables on the odds of timely health visits, and proportionalhazards regression will explore the effects on time to first health visits.

Ethics and dissemination Ethical and data custodian approval has been obtained for this study. Dissemination will include presentation of findings to policy and service stakeholders in addition to scientific papers.

\section{INTRODUCTION}

The statutory removal of children experiencing neglect and/or abuse and placement into out-of-home care (OOHC) is common

\section{What is known on this subject}

Children and young people entering out-of-home care (looked after children) have high rates of health problems in all domains of health.

- International peak bodies and Australian nationa guidelines recommend timely assessment of health needs following entry to out-of-home care.

- There are no data available that describe the timing or extent of health service use by children following their entry to out-of-home care.

\section{What this study adds}

This protocol paper describes a retrospective statewide cohort study identifying health services use by new entrants to care over a five year period.

- This study will be the first to examine timing and extent of health service use by Australian children in out-of-home care using administrative datasets.

- This study will use both state and federal health datasets to capture health service visits across primary health services and hospital based services.

to many child protection systems. Such care can be with extended family (kinship care) or with trained care providers (foster care) or in residential units. International studies show that children entering OOHC (also known as 'looked after children') have higher rates of physical,${ }^{1-5}$ mental $^{6-10}$ and developmental ${ }^{4911}$ health needs than the general population. Australian studies replicate these findings, in metropolitan and regional settings, and for Indigenous and non-Indigenous children in care. ${ }^{12-16}$ This is unsurprising, as reasons for removal from birth family are risk factors known to adversely affect development, health and well-being. Poor health negatively 
impacts on well-being, in childhood and long term, directly and indirectly: poor health in childhood negatively impacts on school performance, and poor educational outcomes lead to poorer health in adulthood. ${ }^{17}$ Early identification and management of health and developmental needs optimises long-term outcomes and minimises cost. This rationale underpins global expert bodies' recommendations for early, routine health assessment of children on their entry to OOHC. ${ }^{18-20}$

If high health needs are routinely identified on entry to care, then high rates of health service use should follow. Some studies have shown such high rates (compared with children of similar socioeconomic background) for mental health service use ${ }^{21-24}$ psychotropic drug use, ${ }^{25}$ well-child visits ${ }^{25}$ and hospitalisations. ${ }^{24}$ In Australia, Tarren-Sweeney found higher rates of mental health service use by children in OOHC in New South Wales even when compared with other children in OOHC, possibly due to a dedicated psychology service for children in OOHC in addition to universal school counselling services. ${ }^{26}$

However, there are concerns that both routine health checks and overall health service use is lower than it ought to be, given the level of need. Rates of timely initial health checks are often low: in Delaware, only $31 \%$ of children in care received a timely initial health check, ${ }^{25}$ and a Michigan study aiming to improve rates of timely health checks lifted rates from $27.6 \%$ pre-intervention to $52.2 \%$ post-intervention. ${ }^{27}$ In 2000 , a UK study reported $65 \%$ of children having a timely health visit, ${ }^{28}$ and in Australia, an audit of case files in New South Wales showed that $22.1 \%$ had recorded an initial health assessment within 60 days. ${ }^{29}$ Melbye et al reported that most children in care received no dental care during a 12-month period, ${ }^{30}$ and those in kinship care were less likely than those in foster care to have received dental care. This care-type difference was also shown in Florida for likelihood of receiving mental health services. ${ }^{31}$

The myriad reasons for lower-than-expected routine health assessment and health service use have long been discussed. Over 25 years ago, Combs-Orme et al applied a health service use theoretical model to children in foster care and found barriers to healthcare in all domains of the model: health policy, healthcare delivery system characteristics and population characteristics. ${ }^{32}$ The challenges described-timely access, funding, health information management and legal responsibility for healthcare sitting with statutory authorities rather than the carersstill hinder timely and comprehensive healthcare. ${ }^{29} 33$

Despite the challenges, routine assessment for identification of health needs continues to be recommended by peak bodies and policy-makers in the USA, the UK and New Zealand. ${ }^{18-20}{ }^{34}$ It was recommended in Australia in $2011^{35}$ although no data are available to assess progress. Within Australia, state governments are responsible for child protection services and some health services (including hospitals and community health services). Approaches to the provision of health services to children in OOHC vary. In Victoria, there is no state-wide service providing routine assessment nor any means of determining the needs and access to health service for these highly vulnerable children. Data linkage provides the only option for understanding recent practice and to evaluate the impact of previous policy and programme interventions.

\section{AIM}

This study aims to describe the extent and timeliness of health service use by Victorian children (aged 0-12 years) who entered OOHC for the first time between 1 April 2010 and 31 December 2015, in the first 12 months of care.

\section{Research questions}

1. What proportion of children in the cohort attended health services within the recommended time frame?

2. What was the median time to health assessment (for initial general practitioner (GP) visit, initial paediatrician visit, dentist, audiology, optometry visits)?

3. Was timeliness of attendance affected by the introduction of the National Clinical Assessment Framework or the Pathway to Good Health programme?

4. What was the health service use of Victorian children aged $0-12$ years who entered OOHC for the first time, staying at least 3 months, within the first year of care?

5. Which factors are associated with improved timeliness of health visits and extent of health service use?

\section{METHODS AND ANALYSIS \\ Design}

Retrospective cohort data linkage study.

\section{Sample selection and size}

The sample will be identified in the government-held Victorian Child Protection Client Relationship Information System (CRIS). It will include all children aged $0-12$ years inclusive, who were placed in an OOHC placement in the state of Victoria, Australia, for the first time between 1 April 2010 and 31 December 2015, and who remained in OOHC for at least 3 months. The expected size of the cohort is difficult to determine given the lack of available data on length of placement in OOHC for firsttime entrants. However, extrapolating available statistics (number of children entering OOHC and proportion in care for a duration of between 1 month and 1 year), we estimate the cohort might include around 2000 children.

\section{Data sources}

Table 1 provides details of the seven state and one federal database from which data will be extracted and linked. Child and placement variables will be obtained from the Child Protection database. Information about healthcare visits will be extracted from health databases. CRIS is the Victorian database to record and manage information about children within the Child Protection system. CRIS 
Table 1 Data sources

\begin{tabular}{|c|c|c|}
\hline Dataset & Data description & Provider \\
\hline $\begin{array}{l}\text { Client Relationship } \\
\text { Information System }\end{array}$ & $\begin{array}{l}\text { Register of all children known to Child Protection. Includes } \\
\text { demographic details about the children, reasons for entry to } \mathrm{OOHC} \\
\text { and details for episodes of OOHC (dates, care type, geographical } \\
\text { area, foster care agency involved). }\end{array}$ & $\begin{array}{l}\text { Department of Health and } \\
\text { Human Services, Victoria }\end{array}$ \\
\hline $\begin{array}{l}\text { Medicare Benefits } \\
\text { Schedule (MBS) claims } \\
\text { data }\end{array}$ & $\begin{array}{l}\text { Record of services that qualified for a Medicare Benefit and for which } \\
\text { a claim was processed. Includes dates, provider type and postcode, } \\
\text { item numbers that identify visit type and length. }\end{array}$ & $\begin{array}{l}\text { Department of Health, } \\
\text { Canberra (via AlHW) }\end{array}$ \\
\hline $\begin{array}{l}\text { Dental Health Program } \\
\text { Dataset }\end{array}$ & $\begin{array}{l}\text { Data set composed of reports of all dental assessments and } \\
\text { treatments provided to eligible clients by funded organisations. } \\
\text { Includes dates of visits, dental treatment items and provider type. }\end{array}$ & $\begin{array}{l}\text { Department of Health and } \\
\text { Human Services, Victoria }\end{array}$ \\
\hline $\begin{array}{l}\text { Community Health } \\
\text { Minimum Dataset }\end{array}$ & $\begin{array}{l}\text { Dataset of community health service visits, including dates of visits, } \\
\text { service types, reasons for attendance. }\end{array}$ & $\begin{array}{l}\text { Department of Health and } \\
\text { Human Services, Victoria }\end{array}$ \\
\hline $\begin{array}{l}\text { Victorian Emergency } \\
\text { Minimum Dataset }\end{array}$ & $\begin{array}{l}\text { Dataset of public hospital emergency department visits, including } \\
\text { timing, diagnoses, triage category. }\end{array}$ & $\begin{array}{l}\text { Department of Health and } \\
\text { Human Services, Victoria }\end{array}$ \\
\hline $\begin{array}{l}\text { Client Management } \\
\text { Interface/Operational } \\
\text { Dataset }\end{array}$ & $\begin{array}{l}\text { Dataset for public mental health services, including outpatient visits } \\
\text { and admissions, diagnoses and type of services. }\end{array}$ & $\begin{array}{l}\text { Department of Health and } \\
\text { Human Services, Victoria }\end{array}$ \\
\hline $\begin{array}{l}\text { Victorian Admitted } \\
\text { Episodes Dataset }\end{array}$ & $\begin{array}{l}\text { Dataset for admissions to Victorian public and private hospitals, } \\
\text { including timing and diagnoses. }\end{array}$ & $\begin{array}{l}\text { Department of Health and } \\
\text { Human Services, Victoria }\end{array}$ \\
\hline $\begin{array}{l}\text { Victorian Integrated Non- } \\
\text { admitted Health dataset }\end{array}$ & $\begin{array}{l}\text { Dataset from public hospital outpatient clinics that include dates of } \\
\text { visits, type of setting, MBS charges (if applied), professional group, } \\
\text { purpose of service. }\end{array}$ & $\begin{array}{l}\text { Department of Health and } \\
\text { Human Services, Victoria }\end{array}$ \\
\hline
\end{tabular}

AlHW, Australian Institute of Health and Welfare; $\mathrm{OOHC}$, out-of-home care.

captures all Victorian children placed in OOHC. The six Victorian health databases are administrative databases that collate data reported from health services visits and admissions.

Medicare is a federally funded healthcare scheme that subsidises or fully funds visits to doctors, specialists, optometrists, dentists and some allied health practitioners. All Australians are eligible. The Medicare Benefits Schedule Claims Dataset contains information on visits for which a Medicare billing claim has been processed, including the date and type of health service accessed.

\section{Data linkage}

The Centre for Victorian Data Linkage (CVDL) will identify the study cohort within the CRIS database, and extract demographic and placement variables. CVDL will then identify records that link to the study population in the six state-based datasets. The Australian Institute of Health and Welfare (AIHW) Data Integration Services Centre (DISC) will conduct the linkage to the Medicare Benefits Schedule (MBS) dataset, using the project-specific ID and identifiers. Figure 1 outlines the data linkage processes.

CVDL uses deterministic linkage, applying a series of business rules to 'determine' whether two (or more) records belong to the same person. CVDL also uses some 'fuzzy matching' to pick up slight variations in identifiers (eg, names recorded as Robert and Bob). CVDL undertakes both data linkage and integration and applies the separation principle within the CVDL team itself, using separate teams to (1) work with identifying data to link records belonging to the same individuals across multiple datasets and generate a linkage key and (2) integrate the de-identified content (service history) data. AIHW uses probabilistic linkage and applies the separation principle by also using separate teams within DISC to perform linkage and integration. The researcher undertaking data analysis will then only access de-identified and appropriately confidentialised integrated datasets through a secure research access environment.

\section{Interventions}

The National Clinical Assessment Framework for Children and Young People in Out-of-Home Care (December 2011).

Standard 5 of the National Standards for out-of-home care states that 'Children and young people have their physical, developmental, psychosocial and mental health needs assessed and attended to in a timely way'. ${ }^{35}$ The National Clinical Assessment Framework indicates that a preliminary health check should occur no later than 30 days after entry to OOHC, and a comprehensive health and developmental assessment should be completed within 3 months of entry. ${ }^{36}$

\section{Pathway to Good Health programme (PTGH) (May 2013)}

This programme was designed to implement the National Standards in parts of Victoria. General practices were recruited to provide a medical home and timely initial health checks. Multidisciplinary clinics were established 
Obtain ethics approvals and data custodian permissions to access data

- Royal Children's Hospital Human Research Ethics Committee

- Centre for Victorian Data Linkage (CVDL) (Data Custodian: Minister for Families and Children)

- Australian Institute of Health and Welfare (AlHW) Ethics Committe

- Public Interest Certificate (Commonwealth Department of Health)

\section{Data linkage process: Identify cohort:}

(children aged $0-12$ years who have entered out-of-home care for the first time in Victoria on any date between 1 April 2010 and 31 $31^{\text {st }}$ December 2015, and who stayed in out-of-home care for at least three months)

(to be done by Centre for Victorian Data Linkage through access to Child Protection

CRIS database - a cohort Participant ID and identifiers will be established)

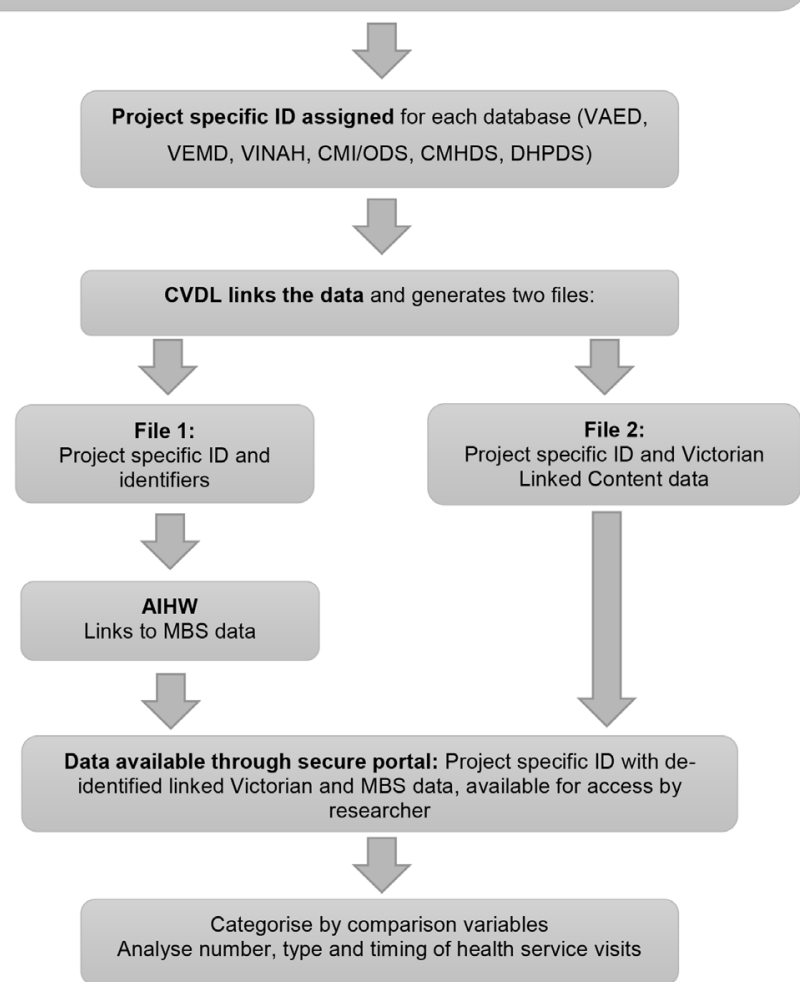

Figure 1 Data linkage process. CHMDS, Community Health Minimum Dataset; CMI/ODS, Client Management Interface/ Operational Dataset; CRIS, Client Relationship Information System; DHPDS, Dental Health Program Dataset; MBS, Medicare Benefits Schedule; VAED, Victorian Admitted Episodes Dataset; VEMD, Victorian Emergency Minimum Dataset; VINAH, Victorian Integrated Non-admitted Health dataset.

at the Royal Children's Hospital and two community health centres to perform comprehensive assessments approximately 3 months following entry to OOHC. Each clinic has a paediatrician, psychologist and speech pathologist who assess the child and provide a Health Management Plan. Vision and dental assessments are also recommended for all children. All local first-time entrants to OOHC after November 2012 were eligible for clinic assessments, and the first children were seen May 2013. While some data are available from the PTGH clinics about the children that have been seen, nothing is known about what services the remaining children are receiving and when they are receiving them.
Table 2 Measures of health service use

\begin{tabular}{lll}
\hline Measure & Data source & $\begin{array}{l}\text { Outcome } \\
\text { measured }\end{array}$ \\
\hline GP attendance & $\begin{array}{l}\text { Medicare billing } \\
\text { data }\end{array}$ & $\begin{array}{l}\text { Total no and type } \\
\text { of GP visits }\end{array}$ \\
$\begin{array}{l}\text { Paediatrician } \\
\text { attendance }\end{array}$ & $\begin{array}{l}\text { Medicare billing } \\
\text { data }\end{array}$ & $\begin{array}{l}\text { Total no and } \\
\text { type of specialist } \\
\text { physician visits }\end{array}$ \\
$\begin{array}{l}\text { Audiology } \\
\text { assessment }\end{array}$ & $\begin{array}{l}\text { Medicare billing } \\
\text { data }\end{array}$ & $\begin{array}{l}\text { Total no of } \\
\text { audiology } \\
\text { attendances }\end{array}$ \\
Dental assessment & $\begin{array}{l}\text { DHPDS database } \\
\text { Optometry }\end{array}$ & $\begin{array}{l}\text { Total no of dental } \\
\text { visits }\end{array}$ \\
assessment & $\begin{array}{l}\text { Medicare billing } \\
\text { data }\end{array}$ & $\begin{array}{l}\text { Total no of } \\
\text { optometry visits }\end{array}$ \\
\hline Mental health visits & $\begin{array}{l}\text { Medicare billing } \\
\text { data (psychiatry, } \\
\text { psychology, GP } \\
\text { mental health } \\
\text { visits) }\end{array}$ & $\begin{array}{l}\text { Total no of } \\
\text { mental health } \\
\text { attendances; } \\
\text { subtotals for }\end{array}$ \\
& $\begin{array}{l}\text { health service as } \\
\text { recorded in CMI/ } \\
\text { ODS }\end{array}$ & different services \\
\hline
\end{tabular}

\begin{tabular}{|c|c|c|}
\hline $\begin{array}{l}\text { Community health } \\
\text { centre visits }\end{array}$ & CHMDS database & $\begin{array}{l}\text { No and type of } \\
\text { community health } \\
\text { services }\end{array}$ \\
\hline ED attendances & VEMD & $\begin{array}{l}\text { Total no of visits } \\
\text { to ED }\end{array}$ \\
\hline $\begin{array}{l}\text { Hospital } \\
\text { admissions }\end{array}$ & VAED & $\begin{array}{l}\text { Total no of } \\
\text { admissions } \\
\text { to hospital }\end{array}$ \\
\hline $\begin{array}{l}\text { Hospital outpatient } \\
\text { clinic attendances }\end{array}$ & VINAH & $\begin{array}{l}\text { Total no of } \\
\text { outpatient clinic } \\
\text { attendances and } \\
\text { type of clinic }\end{array}$ \\
\hline
\end{tabular}

CHMDS, Community Health Minimum Dataset; CMI/ODS, Client Management Interface/Operational Dataset; DHPD, Dental Health Program Dataset; ED, emergency department; GP, general practitioner; VAED, Victorian Admitted Episodes Dataset; VEMD, Victorian Emergency Minimum Dataset; VINAH, Victorian Integrated Non-admitted Health Dataset.

\section{Outcomes}

The outcomes of interest are overall health service use in the first 12 months after entry to OOHC and timely health visits, particularly to a GP, paediatrician, dentist, audiologist and optometrist. Table 2 outlines outcome measures of health service use.

Timeliness will be defined by the National Clinical Assessment Framework. The initial GP visit following entry to care will be counted as the initial health check, expected within 30 days of entering OOHC. The initial audiology, optometry and dental visits will be considered to fulfil hearing, vision and dental checks, expected within 3 months of entry to OOHC. An initial specialist physician visit or an extended GP visit that follows an 
Table 3 Explanatory variables

\begin{tabular}{ll}
\hline Type & Variable \\
\hline Child & Sex \\
& $\begin{array}{l}\text { Age } \\
\text { Aboriginal and Torres Strait } \\
\text { Islander status }\end{array}$ \\
\hline Reason for entry to OOHC & $\begin{array}{l}\text { Primary substantiated abuse } \\
\text { Secondary substantiated } \\
\text { abuses }\end{array}$ \\
Care system & $\begin{array}{l}\text { Care type (foster, kinship, } \\
\text { residential, other) } \\
\text { Agency } \\
\text { Region (metropolitan, } \\
\text { regional, rural) }\end{array}$ \\
\hline
\end{tabular}

$\mathrm{OOHC}$, out-of-home care.

initial visit will be considered to fulfil the comprehensive health check, also expected within 3 months.

\section{Data analysis plan}

The timeliness of visits will be analysed by determining the proportion to meet national standards, the median time to first attendance with a provider following entry to $\mathrm{OOHC}$ and the proportion with no attendance within 12 months following entry to OOHC. Survival curves for time to first visits with specific provider types will be generated.

To determine whether the policy or programme interventions impacted the timeliness of health service use, the cohort will be divided into subcohorts for comparison. Risk ratios and risk differences will be used to compare the probability of meeting the national standards both before and after the interventions and between areas that had access to the PTGH programme and those that did not.

Descriptive statistics will be used to report on the extent of health service use for each child over the initial 12-month period of care: number of visits to each health service (mean, median and range, for the entire cohort, and for those who attended each service). As some of the cohort will exit OOHC before 12 months, analysis and interpretation will depend on the pattern and proportion of children exiting the cohort and adjusted accordingly.

The cohort will be analysed by child and care system explanatory variables (see table 3) to identify those which are potentially significant. Such variables will be included in a multivariable logistic regression model to examine the effects on the odds of timely health visits and in a proportional-hazards regression model to examine the effects on the time to first health visit for different services.

\section{Patient and public involvement}

Neither patients nor the public have been involved in the study design.

\section{Governance, ethics and dissemination plan}

To guide interpretation of findings and use in service planning, the project steering group includes policy stakeholders from relevant government departments, health and child welfare sectors and community service organisations including an Aboriginal Controlled Community Organisation.

Findings will be disseminated through the Outcomes Practice Evidence Network of the Centre for Excellence in Child and Family Welfare, scientific papers and presentations at conferences.

\section{DISCUSSION}

\section{Limitations}

The accuracy of identifiers will determine the quality of data linkage. Some health visits may not be detected if some of these identifiers were not consistent across services. Potentially, some early visits may not have been billed to Medicare if the child's Medicare number was unknown. These limitations would underestimate the timeliness and extent of health service use.

The quality of each dataset will need to be determined; some state-based datasets may not capture all relevant health visit types and may underestimate health service use.

We will analyse the cohort by Aboriginal and Torres Strait Islander status. This will be determined within CRIS. Aboriginal children may be underidentified in this cohort. While there is now policy and practice emphasis on identifying Aboriginal children to ensure they receive culturally appropriate care, this may have been less in 2010. Additionally, Aboriginal children may receive their healthcare at Aboriginal Controlled Community Health Organisations (ACCHOs). While Medicare MBS billing is used by ACCHOs for medical and some other services, services do not routinely report other visits into the study datasets which may underdetect some health service use. This could limit the interpretation of results for some types of health services for Aboriginal children.

While all children entering OOHC ought to have health needs assessed and addressed, this study will include only those entering for the first time and remaining in OOHC for at least 3 months. Some children have briefer stays, never to re-enter, and some children have multiple episodes of care of variable duration. The focus in this study is those who stayed long enough to have health needs assessed as per the national standards. The 12-month time frame following entry to OOHC was deemed adequate for health needs to be identified (even after 3 months) with some follow-up. Prior to accessing the data, the pattern of exit within the 3-month to 12-month time frame is unknown.

It will not be possible to directly analyse whether the extent of health service use is in proportion to actual morbidity load. Such interpretation will rely on local and international morbidity data from audits of smaller OOHC cohorts. We will also be unable to determine the impact of assessment on health outcomes. 


\section{CONCLUSION}

Children entering OOHC are highly vulnerable, with high rates of physical, developmental and mental health problems. Assessment of health needs ought to be routine and timely to enable early detection and management for optimal outcomes. While Victorian policy supports such practice, little is known about the extent and timeliness of health service use for this cohort. This study will provide the first such state-wide report, over a 5-year time frame, using both state and federal health datasets to provide a comprehensive study of health service use. We expect to be able to identify which child or care system variables, if any, are associated with timely health assessment. The study will also explore the impact (if any) of the national standards and the Pathway to Good Health Programme.

\section{Author affiliations}

${ }^{1}$ Policy and Equity, Murdoch Children's Research Institute, Parkville, Victoria, Australia

${ }^{2}$ Centre for Community Child Health, Royal Children's Hospital, Parkville, Victoria, Australia

${ }^{3}$ Department of Paediatrics, University of Melbourne, Parkville, Victoria, Australia

${ }^{4}$ Health Services, Murdoch Children's Research Institute, Parkville, Victoria, Australia

${ }^{5}$ Health Services Research Unit, Royal Children's Hospital, Parkville, Victoria, Australia

${ }^{6}$ Department of Social Work, Health Sciences, University of Melbourne, Parkville, Victoria, Australia

Contributors KM led the writing of this paper. All authors contributed to the design of the study and the writing of this paper, and approved the final draft.

Funding This research is supported by a Learning System Grant from the Centre for Excellence in Child and Family Welfare, the Child Health and Wellbeing Unit, Department of Health and Human Services, Victoria and the Victorian Government's Operational Infrastructure Support Program. KM is supported by an Australian Government Research Training Program Scholarship PhD scholarship and Murdoch Children's Research Institute scholarship. SG is supported by Australian National Health and Medical Research Council (NHMRC) Career Development Fellowship 1082922. HH is supported by Australian National Health and Medical Research Council (NHMRC) Career Development Fellowship 1136222.

Competing interests Not required.

Patient consent for publication Not required.

Ethics approval Ethics approval has been granted by the Royal Children's Hospital Melbourne Human Research Ethics Committee (HREC no. 37208A, 24 October 2017) and the Australian Institute of Health and Welfare Ethics Committee (E02017/5/405, 5 December 2017). Approval has been granted by the Data Custodian in Victoria and a public interest certificate signed for the MBS billing data.

Provenance and peer review Not commissioned; externally peer reviewed.

Open access This is an open access article distributed in accordance with the Creative Commons Attribution Non Commercial (CC BY-NC 4.0) license, which permits others to distribute, remix, adapt, build upon this work non-commercially, and license their derivative works on different terms, provided the original work is properly cited, appropriate credit is given, any changes made indicated, and the use is non-commercial. See: http://creativecommons.org/licenses/by-nc/4.0/.

\section{REFERENCES}

1 Deutsch SA, Fortin K. Physical health problems and barriers to optimal health care among children in foster care. Curr Probl Pediatr Adolesc Health Care 2015;45:286-91.

2 Dubowitz H, Feigelman S, Zuravin S, et al. The physical health of children in kinship care. Am J Dis Child 1992;146:603-10.

3 Flaherty EG, Weiss $\mathrm{H}$. Medical evaluation of abused and neglected children. Am J Dis Child 1990;144:330-4.
4 Leslie LK, Gordon JN, Meneken L, et al. The physical, developmental, and mental health needs of young children in child welfare by initial placement type. J Dev Behav Pediatr 2005;26:177-85.

5 Olivan G. Untreated dental caries is common among 6 to 12-yearold physically abused/neglected children in Spain. Eur J Public Health 2003;13:91-2.

6 Teggart T, Menary J. An investigation of the mental health needs of children looked after by Craigavon and Banbridge Health and Social Services Trust. Child Care in Practice 2005;11:39-49.

7 Williams J, Jackson S, Maddocks A, et al. Case-control study of the health of those looked after by local authorities. Arch Dis Child 2001;85:280-5.

8 Egelund T, Lausten M. Prevalence of mental health problems among children placed in out-of-home care in Denmark. Child Fam Soc Work 2009;14:156-65.

9 Deutsch SA, Lynch A, Zlotnik S, et al. Mental health, behavioral and developmental issues for youth in foster care. Curr Probl Pediatr Adolesc Health Care 2015;45:292-7.

10 Conn A-M, Szilagyi MA, Alpert-Gillis L, et al. Mental health problems that mediate treatment utilization among children in foster care. $J$ Child Fam Stud 2016;25:969-78.

11 Ford T, Vostanis P, Meltzer H, et al. Psychiatric disorder among British children looked after by local authorities: comparison with children living in private households. $\mathrm{Br} J$ Psychiatry 2007;190:319-25.

12 Raman S, Reynolds S, Khan R. Addressing the well-being of Aboriginal children in out-of-home care: are we there yet? $J$ Paediatr Child Health 2011;47:806-11.

13 Sawyer MG, Carbone JA, Searle AK, et al. The mental health and wellbeing of children and adolescents in home-based foster care. Med J Aust 2007;186:181-4.

14 Tarren-Sweeney M, Hazell P. Mental health of children in foster and kinship care in New South Wales, Australia. J Paediatr Child Health 2006;42:89-97.

15 Nathanson D, Tzioumi D. Health needs of Australian children living in out-of-home care. J Paediatr Child Health 2007;43:695-9.

16 Arora N, Kaltner M, Williams J. Health needs of regional Australian children in out-of-home care. J Paediatr Child Health 2014;50:782-6.

17 Case A, Fertig A, Paxson C. The lasting impact of childhood health and circumstance. J Health Econ 2005;24:365-89.

18 Royal Australasian College of Physicians. Health of children in "outof-home" care. Sydney: RACP, 2006.

19 Council on Foster Care, Adoption, and Kinship Care, Committee on Adolescence, and Council on Early Childhood. Health care issues for children and adolescents in foster care and kinship care. Pediatrics 2015;136:e1131-e1140.

20 Department for Education and Department of Health. Promoting the health and well-being of looked-after children: statutory guidance for local authorities, clinical commissioning groups and NHS England. England, 2015

21 Harman JS, Childs GE, Kelleher KJ. Mental health care utilization and expenditures by children in foster care. Arch Pediatr Adolesc Med 2000;154:1114-7.

22 Halfon N, Berkowitz G, Klee L. Mental health service utilization by children in foster care in California. Pediatrics 1992;89:1238-44.

23 Halfon N, Berkowitz G, Klee L. Children in foster care in California: an examination of Medicaid reimbursed health services utilization. Pediatrics 1992;89:1230-7.

24 Takayama JI, Bergman AB, Connell FA. Children in foster care in the state of Washington. Health care utilization and expenditures. JAMA 1994:271:1850-5.

25 Knight EK, McDuffie MJ, Gifford K, et al. Health service utilization of children in delaware foster care, 2013-2014. Del Med J 2016;88:46-52.

26 Tarren-Sweeney M. Concordance of mental health impairment and service utilization among children in care. Clin Child Psychol Psychiatry 2010;15:481-95

27 Day A, Curtis A, Paul R, et al. Timely health service utilization of older foster youth by insurance type. J Adolesc Health 2016;58:17-23.

28 Acharyya S. Promoting health of looked after children. Monitoring and documentation should be improved. BMJ 2000;321:381.

29 Vimpani G, Boland K, Barr M, et al. Children in out-of-home care in NSW: what do their case files tell us about their health care? Developing Practice 2012;30:53-62.

30 Melbye ML, Chi DL, Milgrom P, et al. Washington state foster care: dental utilization and expenditures. J Public Health Dent 2014;74:93-101.

31 Swanke JR, Yampolskaya S, Strozier A, et al. Mental health service utilization and time to care: a comparison of children in traditional 
foster care and children in kinship care. Child Youth Serv Rev 2016;68:154-8.

32 Combs-Orme T, Chernoff RG, Kager VA. Utilization of health care by foster children: application of a theoretical model. Child Youth Serv Rev 1991;13:113-29.

33 Risley-Curtiss C, Stites B. Improving healthcare for children entering foster care. Child Welfare 2007;86:123-44.

34 Ministry of Social Development. Gateway assessment service: service specification. New Zealand, 2015.
35 Department of Families, Housing, Community Services and Indigenous Affairs together with the National Framework Implementation Working Group. An outline of National Standards for Out-of-home Care. Canberra, 2011.

36 Child Health and Wellbeing Subcommittee Australian Population Health Development Principal Committee. National Clinical Assessment Framework for Children and Young People in Out-ofHome Care (OOHC). Canberra, 2011. 